\title{
Unrealistic energy and materials requirement for direct air capture in deep mitigation pathways
}

\author{
Sudipta Chatterjee $e^{1} \&$ Kuo-Wei Huang (iD) ${ }^{1 凶}$
}

ARISING FROM G. Realmonte et al. Nature Communications https://doi.org/10.1038/s41467-019-10842-5 (2019).

T he increasing global atmospheric $\mathrm{CO}_{2}$ concentration due to heavy reliance on fossil fuels as the primary energy sources $(\sim 410 \mathrm{ppm} \text { in } 2019)^{1}$ has made direct extraction or removal of $\mathrm{CO}_{2}$ from ambient air (direct air carbon capture (DACC)) the most logical alternative over traditional modes of carbon capture from large stationary sources because of many of the perceived advantages and compelling arguments ${ }^{2}$. With the current level of $\mathrm{CO}_{2}$ emissions (32.6 gigatons (Gt)- $\left.\mathrm{CO}_{2} / \mathrm{year}_{2017}\right)^{1}$, Realmonte and co-workers recently imposed the global capacity at $30 \mathrm{Gt}-$ $\mathrm{CO}_{2}$ /year as a case study for DACC, and concluded that "in theory DACCS can be an enabling factor for the Paris Agreement objectives" and recommended the policy makers to "support an acceleration in development and deployment of DACCS"3. While challenges of large-scale $\mathrm{CO}_{2}$ utilization and sequestration were recognized and these approaches were deemed impractical ${ }^{4,5}$, our analysis further showed that the energy and materials requirements for DACC are unrealistic even when the most promising technologies are employed. Thus, DACC is unfortunately only an energetically and financially costly distraction in effective mitigation of climate changes at a meaningful scale before we achieve the status of a significant surplus of carbon-neutral/low-carbon energy.

The urgent need for a large amount of $\mathrm{CO}_{2}$ removal by DACC has been recognized since the Intergovernmental Panel on Climate Change (IPCC)'s assessment report in $2013^{6}$. This rapidly growing field has thus attracted industrial, academic and political attention over the last decades, ultimately pushing DACC technologies from lab scale to pilot scale with multi-billion dollars of investments and research funding from the private and governmental sectors ${ }^{7}$. Realmonte et al. have investigated the roles of DACC utilizing two integrated assessment modelling (IAM) studies on DAC1 (based on aqueous hydroxide solutions of $\mathrm{NaOH}, \mathrm{KOH}$, etc.) and DAC2 (based on amine-modified solid sorbents such as monoethanolamine (MEA)) as the most promising methods (Fig. 1). Detailed techno-economic characteristics have been incorporated based on the latest available literature estimates aiming to meet the Paris Agreement objectives to keep global warming well below $2{ }^{\circ} \mathrm{C}$ (i.e. removal of 30 Gt- $\mathrm{CO}_{2} /$ year). However, to fully assess the feasibilities of DACC technologies, the energy cost for manufacturing materials must be considered.

The total energy requirement to reach the capacity of capturing $30 \mathrm{Gt}-\mathrm{CO}_{2} / \mathrm{yr}$ was estimated based on the production of the needed materials as reasonably proposed by Realmonte et al. considering the make-up rates of sorbents of $0.17-0.29 \mathrm{t} / \mathrm{t}_{\mathrm{CO} 2}$ of $\mathrm{NaOH}$ in $\mathrm{DACl}^{8}$ and a similar replacement rate for MEA in DAC2. For DAC1, $5.1-8.7 \mathrm{Gt} / \mathrm{yr}$ of $\mathrm{NaOH}$ is required, and the production will need 2.15-3.67 $\mathrm{TW}_{\mathrm{e}}$-yr (electrical energy for electrolysis $=13.3 \mathrm{GJ}_{\mathrm{e}} /$ $\left.\mathrm{t}_{\mathrm{NaOH}}\right)^{9}$ (Fig. 2a, b). This will account for about $12-20 \%$ of total global energy supply (TGES; $18.55 \mathrm{TW}$-yr for 2017, but likely greater than the global electricity generation capacity of $\left.2.92 \mathrm{TW}_{\mathrm{e}}-\mathrm{yr}\right)^{10}$. One also notes that the industrial electrolysis process, associated with $\mathrm{NaOH}$ production in DAC1, will result in the production of a huge amount of $\mathrm{Cl}_{2}$ gas (4.6-7.9 Gt), far exceeding the current utilization capacity $\left(76.8 \mathrm{Mt} \mathrm{Cl}_{2} / \mathrm{yr}\right)$ and posing risks which are difficult to evaluate a priori. In addition to the materials production energy cost, sorbents regeneration also drag a significant amount of heat and electricity. While DAC1 employs the less "energy-intensive" $\mathrm{NaOH}$, the necessity of high temperature $\left(>800^{\circ} \mathrm{C}\right)$ for regeneration induces a larger energy usage $\left(6.57-9.9 \mathrm{G} \mathrm{J}_{\mathrm{tota} a} / \mathrm{t}_{\mathrm{CO} 2}\left(1.32-1.8 \mathrm{GJ}_{\mathrm{e}} / \mathrm{t}_{\mathrm{CO} 2}\right.\right.$ and $\left.5.25-8.1 \mathrm{GJ}_{\mathrm{h}} / \mathrm{t}_{\mathrm{CO}}\right), 6.25-9.41 \mathrm{TW}_{\text {total- }}-\mathrm{yr}=34-51 \%$ TGES) (Fig. 2c). In contrast, even though the milder condition for sorbent regeneration in the DAC2 technology costs $~ 50 \%$ of that for DAC1 $\left(3.5-6.6 \mathrm{GJ}_{\mathrm{tota} a} / \mathrm{t}_{\mathrm{CO} 2}\left(0.6-1.1 \mathrm{GJ} / \mathrm{t}_{\mathrm{CO} 2}\right.\right.$ and $\left.2.9-5.5 \mathrm{GJ}_{\mathrm{h}} / \mathrm{t}_{\mathrm{CO} 2}\right), 3.3-6.3$ TW-yr $=18-34 \%$ TGES $)^{11,12}, 16.3-27.8 \mathrm{Gt}$ of $\mathrm{NH}_{3}$ and 3.3-5.6 Gt of ethylene oxide (EO) will be necessary to produce the required amount of MEA (i.e. 5.1-8.7 Gt), which will consume 14.5-24.7 $\mathrm{TW}_{\mathrm{h}}-\mathrm{yr}\left(28 \mathrm{GJ}_{\mathrm{h}} / \mathrm{t}_{\mathrm{NH} 3}\right.$ if produced only from natural gas ${ }^{13}, 78-133 \%$ TGES) or $20.7-35.3 \mathrm{TW}_{\mathrm{e}}-\mathrm{yr}\left(40 \mathrm{GJ}_{\mathrm{e}} / \mathrm{t}_{\mathrm{NH} 3}\right.$ if produced only by electrolysis ${ }^{13}, 112-190 \%$ TGES $)$ and $2.6-4.1 \mathrm{TW}_{\text {total }}-\mathrm{yr}\left(25 \mathrm{GJ}_{\text {total }} / \mathrm{t}_{\mathrm{EO}}\right.$, $14-24 \%$ TGES) ${ }^{14}$, respectively (Fig. 2).

From our analyses, DAC2 is clearly an unsuitable option to capture $30 \mathrm{Gt}-\mathrm{CO}_{2} / \mathrm{yr}$, most likely due to enormous amount of materials (16.3-27.8 Gt of $\mathrm{NH}_{3}$ and 3.3-5.6 Gt of EO) and energy needed (20.4-35.1 TW-yr, 110-191\% TGES if $\mathrm{NH}_{3}$ production from only natural gas is being considered). DAC1 also takes at least 8.4-13.1 TW-yr (46-71\% TGES), excluding the potential environmental risks and the associated energy costs required for

${ }^{1}$ KAUST Catalysis Center and Division of Physical Sciences \& Engineering, King Abdullah University of Science and Technology, Thuwal 23955-6900, Saudi Arabia. ${ }^{凶}$ email: hkw@kaust.edu.sa 


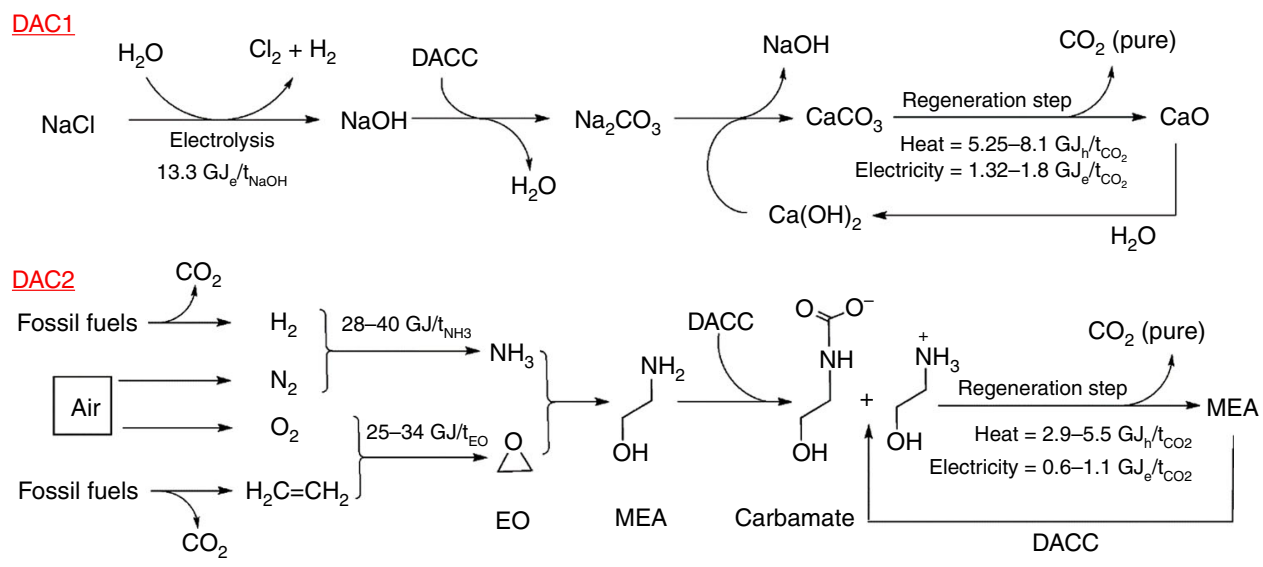

Fig. 1 Schematic representations of direct $\mathbf{C O}_{\mathbf{2}}$ capture from air using sorbents. The outlines of two different DACC technologies (DAC1 and DAC2) are presented with the amounts of electricity and heat energies required for the syntheses of the sorbents ( $\mathrm{NaOH}$ and $\mathrm{MEA})$ from precursors and their regenerations ${ }^{3}$. DACC direct air carbon capture, EO ethylene oxide, MEA monoethanolamine.

a

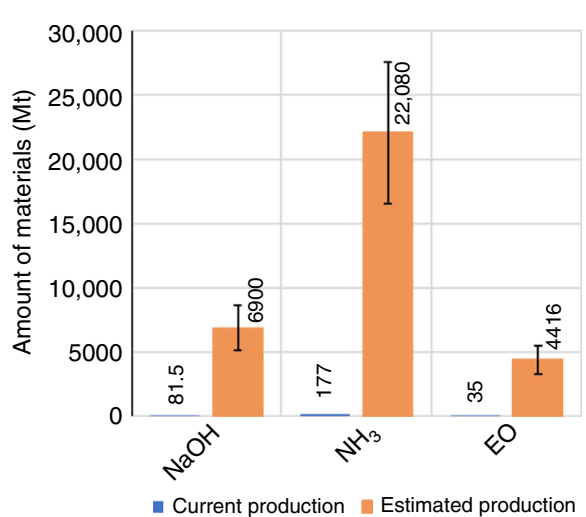

b

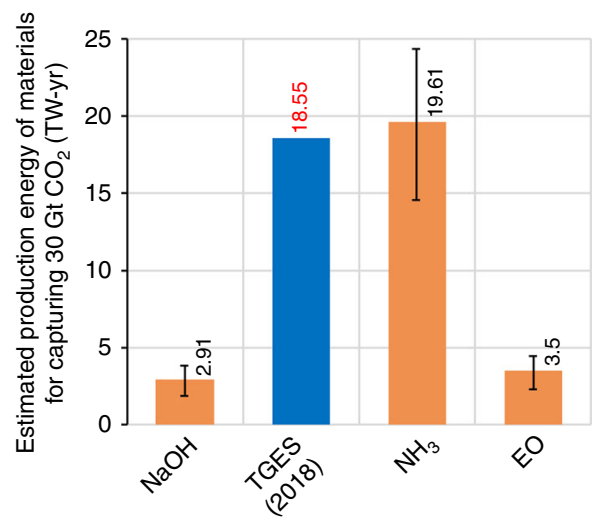

d

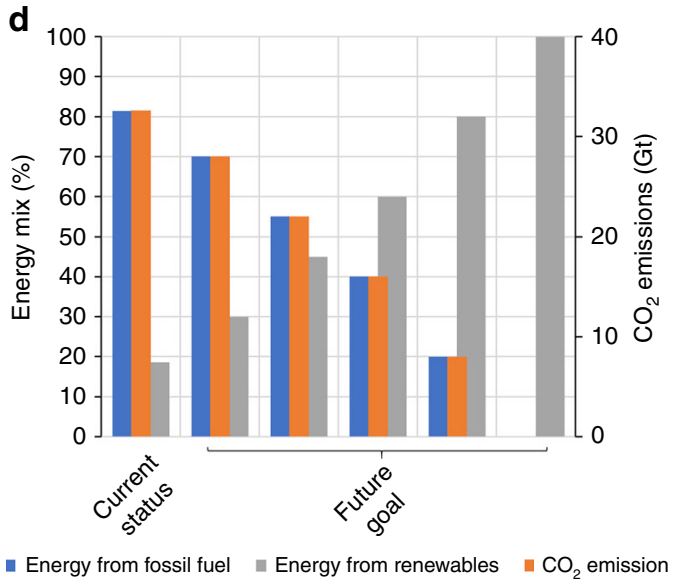

Fig. 2 Energy and materials requirement for DACC-current status and prospects. a Estimated materials required for $\mathrm{CO}_{2}(30 \mathrm{Gt}) \mathrm{capture}$ in $\mathrm{DACC}$ and compared to their current production. Estimated energy required for $\mathbf{b}$ material production and $\mathbf{c}$ sorbent regeneration. $\mathbf{d}$ Current and future energy mix with concomitant $\mathrm{CO}_{2}$ emissions.

carbon storage and utilization (CSU) $)^{4}$. Since the replacement of every $10 \%$ TGES under the current energy status by low-carbon sources, such as nuclear, hydro, wind and solar, can reduce $\sim 4 \mathrm{Gt}-$ $\mathrm{CO}_{2} / \mathrm{yr}$ of emission (Fig. $2 \mathrm{~d}$ ), it is not logical to allocate lowcarbon energy for DACC at present without accelerating the depletion rate of limited fossil fuels.
Considering the projected global energy demand to be increased at least by $50 \%$ before $2050^{15}$, it is imperative that TGES cannot only be invested to harness the $\mathrm{CO}_{2}$ issue. While DACC (and CSU) technologies are an important topic of R\&D and may indeed offer some commercial opportunities with incentivized carbon prices (given the surplus electricity is 
available), before a significant amount of carbon-neutral and/or low-carbon energy can be deployed, any DACC activities will be a significant distraction with negligible contributions to mitigating climate changes. Concentrated efforts on the deployment of lowcarbon energy generation plants across the globe together with raising public awareness to use alternative energy and on the development of technologies in enhancing the energy usage efficiency (e.g. in transportation) must be prioritized to address the pressing twin problems of climate changes and energy security.

Finally, discerning the number of related challenges in DACC and $\mathrm{CSU}^{4,5}$, it is of utmost importance to conduct not only a thorough techno-economic analysis on the future proposed processes but comprehensive assessments on the materials and energy needs at the scale of multi-Gt- $\mathrm{CO}_{2} / \mathrm{yr}$ before a realistic solution can be identified. Wide-ranging discussions/debates between experts from all sectors from all angles are urgently needed.

\section{Data availability}

All relevant data supporting the findings of this study are available within the paper.

Received: 26 November 2019; Accepted: 15 June 2020;

Published online: 03 July 2020

\section{References}

1. International Energy Agency. $\mathrm{CO}_{2}$ Emissions from Fuel Combustion Highlights (OECD Publishing, Paris, 2018).

2. Sanz-Pérez, E. S., Murdock, C. R., Didas, S. A. \& Jones, C. W. Direct capture of $\mathrm{CO}_{2}$ from ambient air. Chem. Rev. 116, 11840-11876 (2016).

3. Realmonte, G. et al. An inter-model assessment of the role of direct air capture in deep mitigation pathways. Nat. Commun. 10, 3277 (2019).

4. Mac Dowell, N., Fennell, P. S., Shah, N. \& Maitland, G. C. The role of $\mathrm{CO}_{2}$ capture and utilization in mitigating climate change. Nat. Clim. Change 7, 243 (2017).

5. Majumdar, A. \& Deutch, J. Research opportunities for $\mathrm{CO}_{2}$ utilization and negative emissions at the gigatonne Scale. Joule 2, 805-809 (2018).

6. IPCC. Climate change 2014: mitigation of climate change. In Contribution of Working Group III to the Fifth Assessment Report of the Intergovernmental Panel on Climate Change (eds Edenhofer, O. et al.) (Cambridge University Press, Cambridge, UK, and New York, 2014).

7. National Academies of Sciences. Engineering and Medicine. Negative Emissions Technologies and Reliable Sequestration: A Research Agenda (The National Academies Press, Washington, DC, 2018).

8. Baciocchi, R., Storti, G. \& Mazzotti, M. Process design and energy requirements for the capture of carbon dioxide from air. Chem. Eng. Process. 45, 1047-1058 (2006).

9. Boulamanti, A. \& Moya, J. A. Energy Efficiency and GHG Emissions: Prospective Scenarios for the Chemical and Petrochemical Industry. EUR 28471 EN, https://doi.org/10.2760/20486 (Publications Office of the European Union, 2017)
10. International Energy Agency. Key World Energy Statistics 2019 (OECD Publishing, Paris, 2019).

11. Rochelle, G. et al. Aqueous piperazine as the new standard for $\mathrm{CO}_{2}$ capture technology. Chem. Eng. J. 171, 725-733 (2011).

12. Luis, $\mathrm{P}$. Use of monoethanolamine (MEA) for $\mathrm{CO}_{2}$ capture in a global scenario: consequences and alternatives. Desalination 380, 93-99 (2016).

13. Giddey, S., Badwal, S. P. S., Munnings, C. \& Dolan, M. Ammonia as a renewable energy transportation media. ACS Sustain. Chem. Eng. 5, 10231-10239 (2017).

14. Nimkar Samir, C. Energy analysis of nitric acid ethylene oxide ethylene glycol process and methanol reactor. Conference Proceedings (2016). https://www. semanticscholar.org/paper/Energy-Analysis-of-Nitric-Acid-Ethylene-Oxideand-NimkarSamir/le9a0ab78201344fce7c75aba1038893e9alb3da.

15. Lewis, N. S. \& Nocera, D. G. Powering the planet: chemical challenges in solar energy utilization. Proc. Natl Acad. Sci. USA 103, 15729 (2006).

\section{Acknowledgements}

This work was supported by King Abdullah University of Science and Technology (KAUST)

\section{Author contributions}

K.-W.H. and S.C. carried out the analysis and wrote the manuscript.

\section{Competing interests}

The authors declare no competing interests.

\section{Additional information}

Correspondence and requests for materials should be addressed to K.-W.H.

Peer review information Nature Communications thanks the anonymous reviewer(s) for their contribution to the peer review of this work

Reprints and permission information is available at http://www.nature.com/reprints

Publisher's note Springer Nature remains neutral with regard to jurisdictional claims in published maps and institutional affiliations.

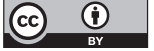

Open Access This article is licensed under a Creative Commons Attribution 4.0 International License, which permits use, sharing, adaptation, distribution and reproduction in any medium or format, as long as you give appropriate credit to the original author(s) and the source, provide a link to the Creative Commons license, and indicate if changes were made. The images or other third party material in this article are included in the article's Creative Commons license, unless indicated otherwise in a credit line to the material. If material is not included in the article's Creative Commons license and your intended use is not permitted by statutory regulation or exceeds the permitted use, you will need to obtain permission directly from the copyright holder. To view a copy of this license, visit http://creativecommons.org/ licenses/by/4.0/

(C) The Author(s) 2020 